\title{
HARNESSING RISKS PERCEPTION THEORY FOR THE UNDERSTANDING OF BARRIERS TO E-GOVERNMENT
}

\author{
Ani Munirah Mohamad ${ }^{1}$ \\ School of Law, Universiti Utara Malaysia, 06010 Sintok, Kedah, Malaysia \\ (Email: animunirah@uum.edu.my) \\ Anis Shuhaiza Md Salleh ${ }^{2}$ \\ School of Law, Universiti Utara Malaysia, 06010 Sintok, Kedah, Malaysia \\ (Email: shuhaiza@uum.edu.my) \\ Mohd Zakhiri Md Nor ${ }^{3}$ \\ School of Law, Universiti Utara Malaysia, 06010 Sintok, Kedah, Malaysia \\ (Email: zakhiri@uum.edu.my) \\ Najah Inani Abdul Jalil ${ }^{4}$ \\ School of Law, Universiti Utara Malaysia, 06010 Sintok, Kedah, Malaysia \\ (Email: najah@uum.edu.my)
}

Accepted date: $30-07-2017$

Published date: 11-07-2019

To cite this document: Mohamad, A. M., Md Salleh, A. S., Md Nor, M. Z., \& Jalil, N. I. A. (2019). Harnessing Risks Perception Theory for The Understanding of Barriers to EGovernment. International Journal of Law, Government and Communication, 4(15), 194-205. DOI: $10.35631 /$ ijlgc. 4150020

\begin{abstract}
The term e-government means the employment of the Internet and the world-wideweb for delivering government information and services to the citizens. It refers to the use by government agencies of information technologies (such as Wide Area Networks, the Internet, and mobile computing) that have the ability to transform relations with citizens, businesses, and other arms of government. Nevertheless, the implementation of e-government has not been smooth-sailing. Managerial hiccups and barriers seem to hamper the proper implementation of e-government. Accordingly, the risks perception theory stands out as being appropriate to explain such barriers. This theoretical paper outlines the application of risks perception theory for the understanding of the barriers to the implementation of e-government in any particular jurisdiction. Factors such as leadership failures, financial inhibitors, and workplace and organizational inflexibility could potentially impede the full potential of the engagement of egovernment services by the government, businesses and the citizens. Adopting library-based research method, and document analysis of secondary data from textbooks, government reports, government websites, journal articles and newspaper reports, this paper traces the development of e-government in selected jurisdictions in the world which adopt e-government in its delivery of information and services. Generally, this paper highlights the employment of risks perception theory in the understanding of the barriers to e-government initiatives. The paper aspires to contribute to the body of knowledge on the study of e-government services.
\end{abstract}

Keywords: Risks Perception, Perceived Risks, Barriers, E-Government 


\section{Introduction}

The terminology "electronic government" or simply, "e-government" is interpreted differently in the literature in relation to the information and communication technology (ICT). For example, the United Nations Survey 2014 defined e-government as "the employment of the Internet and the world-wide-web for delivering government information and services to the citizens". On another note, e-government refers to "the use by government agencies of information technologies (such as Wide Area Networks, the Internet, and mobile computing) that have the ability to transform relations with citizens, businesses, and other arms of government" (Yildiz, 2007).

Nevertheless, with the increasing adoption of e-government in many parts of the world, its implementation has not been smooth-sailing. Managerial problems and barriers hamper the proper implementation of e-government, such as leadership failures, financial inhibitors, and workplace inflexibility (Meijer, 2015). Such problems could be owing to the various risks and challenges as being perceived by the users of the e-government applications. Henceforth, it is submitted that it is significant to understand the risks perception theory in appreciating the barriers to the implementation of e-government in any given jurisdiction.

However, the scarcity of past literature on the engagement of the theory of risks perception in the understanding of barriers to e-government seem to be the major problem which motivates this present study (Tang, et. Al, 2019; Ebrahim \& Irani, 2005). Accordingly, the objective of the study is to harness the risks perception theory in the understanding of the numerous barriers to the proper implementation of e-government. It is hereby submitted that the main elements of the risk's perception theory would be helpful in the understanding and appreciation of the barriers to e-government in any given jurisdiction.

This paper begins by providing an account of the four models of e-government, followed by deliberating on the development of the e-government initiatives in the selected jurisdictions, such as Singapore, Australia, Korea, United Kingdom and Malaysia. The following part elaborates on the theoretical aspect of risks perception in the understanding of the barriers to egovernment implementation. Thereafter, the discussion on the barriers in its implementation is discussed, before concluding with future directions of the research.

\section{Models of E-Government}

Literature have suggested that there are four models of e-government, namely, government-togovernment (hereinafter G2G), government-to-citizens (hereinafter G2C), government-toemployees (hereinafter G2E) and government-to-businesses (hereinafter G2B) (Mfoihaya \& Yusuf, 2015). These models could be summarised into the following Figure 1. Traditionally, the interaction between a citizen or business and a government agency takes place in a government office. With emerging information and communication technologies, it is possible to locate service centres closer to the clients. Such centres may consist of an unattended kiosk in the government agency, a service kiosk located close to the client, or the use of a personal computer in the home or office (Othman, 2005). 


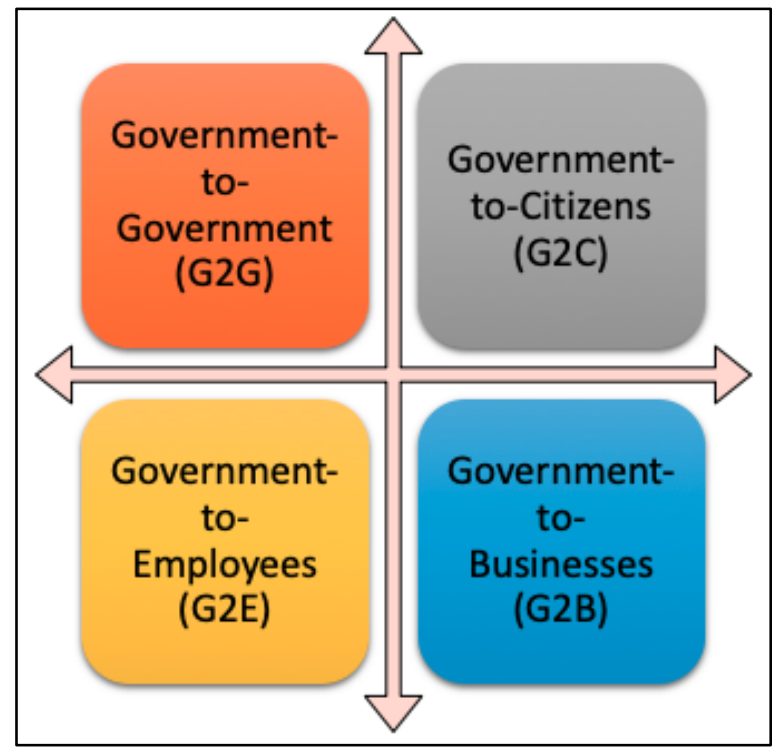

Figure 1. Models of E-Government

In $\mathrm{G} 2 \mathrm{G}$, government agencies interact with each other using the Internet medium and other online tools and sources primarily for information exchange as well as provision of services inter-governmental departments (Nograšek, Vintar \& Irani, 2015). Not only the government services could be improved by internal management of data and relationships, but they can also be seen as effective and efficient in delivering services for the convenient use of the businesses and the citizens (Schnoll, 2015).

Meanwhile, the G2C model applies the strategy of customer relationship management (hereinafter CRM) with business concept. By managing their customer (citizen) relationship, the business (government) can provide the needed products and services fulfil the needs of the customer (Nasim, 2015). In this model, the government provides services and exchanges information directly with the citizens by using the Internet medium and other online sources including social media, electronic mails and online contact forms (Rana, et.al, 2015). Payments to the government can be made online at the comfort of the homes of the citizens, at times convenient to them. Access to information, products or services can be delivered to the citizens using the online medium, which in turn promotes efficiency and effectiveness of the government side.

In G2E model, e-government is the relationship between online tools, sources, and articles that help employees maintain communication with the government and their own companies. The relationship with employees allows new learning technology in one simple place as the computer (Fugini, Maggiolini \& Valles, 2015). Documents can now be stored and shared with other colleagues online, payroll can be generated using softwares and other online system, appraisal and effectiveness of firms can be monitored using e-government tools and sources (Fang, 2002).

As for G2B model, it is the online non-commercial interaction between local and central government and the commercial business sector with the purpose of providing businesses information and advice on e-business 'best practices' (Rita \& Krapfel, 2015). G2B is the transaction through the Internet between government agencies and trading companies. Essentially, G2B allows for professional transactions between the company and the district, city, or federal regulatory agencies (Barret, et.al., 2015). Examples of G2B initiatives are e- 
tenders and e-procurement procedures made available to the businesses by the government. These technologies can serve a variety of different ends including more efficient government management and better delivery of government services to citizens, primarily following the fact that the citizens now do not need to physically attend to the government offices, they could transact with the government even at the comfort of their homes and at their own convenient times (Dahiya \& Mathew, 2015). E-government initiatives also improved interactions with business and industry following the fact that businesses and corporations can now interact with the government using dedicated portals designed for their access (Siddiquee \& Mohamed, 2015). Other than that, citizen empowerment is also improved through access to information, as they can now make informed decisions on just about any particular subject matter especially relating to the information, products or services offered by the government (Wescott, 2001). The resulting benefits can be less corruption, increased transparency, greater convenience, revenue growth, and/or cost reductions (Karim, 2003).

\section{Development of E-Government in Selected Jurisdictions}

Many jurisdictions around the world have embarked upon the e-government initiatives mainly to further improve the delivery of government service to citizens and other entities in dealing with the government. This section traces the development of e-government initiatives in selected jurisdictions, particularly Republic of Korea, Australia, Singapore, United Kingdom and Singapore.

According to the United Nations E-Government Survey 2014, which was completed in January 2014 and made public in June 2014, the top countries in the world leading the e-government initiatives were first, Republic of Korea, followed by Australia, Singapore, France, Netherlands, Japan, United States of America and United Kingdom. This ranking was formulated based on the e-government development index (hereinafter EGDI) which comprised multiple components of online service, telecommunication infrastructure, and human capital index. While the countries mentioned above achieved "very high EGDI" based on the components (more than 0.75), Malaysia fell into the second group of EGDI classification called "high EGDI" (between 0.50 and 0.75) alongside other countries such as China, Egypt, Albania and Saudi Arabia.

Particularly in the Republic of Korea, e-government initiatives began as early as 1980s with the building of National Basic Information System. Further layering of the background for egovernment in mid-1990 until 2000, the government proceeded to build the foundation for high speed information and communications promoting the use of the Internet among the people and the government. The official launch of e-government was made in 2001 with the introduction of the 11 major tasks for e-government and implemented throughout the nation. Between 2003 and 2007, the government further introduced 31 roadmap tasks for e-government initiatives in the country. Additionally, the government promoted the linking and integrating multiple government departments and agencies for better delivery of public service for the people. In 2008, the government established a Master Plan for National Informatisation which has been observed until today and implemented in the entire nation.

In Australia, the Australian Public Service ICT Strategy 2012-2015 was launched in October 2012, aiming to promote the use of ICT to increase public sector and national productivity by enabling the delivery of better government services for the Australian people, communities and business, improving the efficiency of APS operations and supporting open engagement to better inform decisions. Essentially, the Strategy outlines how the Australian Government agencies 
will continue to use ICT to drive better service delivery, improve government operations, drive productivity, and to engage with people, the community and business. It supports better, more accessible government services for people when, where and how it suits them, so they can be more productive.

As for Singapore, the one-stop-portal for e-government services is hosted at www.egov.gov.sg. The portal can be accessed by the public, businesses and the government itself. Essentially, the e-government initiatives in Singapore began its ICT initiatives as early as 1980s when ICT was promoted as the public service efficiency, focusing on the automation of public service and installation of basic IT infrastructure. The e-Government Action Plan I and Plan II were launched between 2000 and 2005, highlighting online service delivery consisting of 1,600 eservices deployed within the five-year tenure. From 2006 until 2010, the Singapore government goes through the 'whole-of' government' integration focusing on integration of data, process and systems for government agencies, embarking upon 300 mobile government services being deployed. The latest stance is the e-Gov 2015 Policy which focuses on the collaboration within and outside government.

In the UK, as early as 1994, the Central Computer \& Telecommunications Agency (hereinafter CCTA), under the responsibility of the UK's Cabinet Office, established a central government website available at www.open.gov.uk, directing Internet users to departmental and agency sites. In 1998, a special report entitled 'Electronic Government: Information Technologies and the Citizen', was published. The report assessed how ICT could be used by the government to improve internal working and the delivery of public services. It was only in April 2000 that the government issued its official e-government strategy called "e-Government: a strategic framework for public services in the Information Age". The states in the UK have made tremendous achievements in delivery public services using the e-government strategies. More than a decade later in 2011, the Minister for the Cabinet Office launched a detailed plan for the implementation of the government's new ICT strategy for the next four years to help deliver better public services digitally. This was followed by the publication of four strategies, namely, 'Government Cloud', 'Greening Government: ICT', 'Government ICT Capability', 'Government End User Device' in October in the same year. Today, all UK government institutions and information have been centralised at a single portal available at www.gov.uk.

In Malaysia, the government launched in 1997 the electronic government initiative to reinvent itself to drive the country into the information age. As far as Malaysia is concerned, the implementation of e-government was initiated with the introduction of the Multimedia Super Corridor (hereinafter MSC) in 1996. The implementation of e-government in Malaysia heralds the beginning of a journey of reinventing the government by transforming the way it operates, modernising and enhancing its service delivery. Over the years, the e-government initiatives in Malaysia have developed more robust and the reaching to all government sectors throughout the nation. The launching of Malaysia's e-government portal www.malaysia.gov.my in 2012 is seen as a serious commitment by the government in facilitating e-government services to the people.

The exploration of the various initiatives of implementing e-government balls down to the main idea of e-government itself, which is the engagement of the Internet and world wide web in providing governmental information and services to the general public. 


\section{Risks Perception Theory and E-Government}

In understanding the theory of risks perception, it is pertinent to first outline the concept of perceived risks. It has previously been defined as "a combination of uncertainty plus seriousness of outcome involved" (Bauer, 1967), and "the expectation of losses associated with purchase (adopt) and acts as an inhibitor to purchase (adopt) behavior', (Peter \& Ryan, 1976). A more recent study defined perceived risks as "the potential for loss in the pursuit of a desired outcome of using an e-service"' (Featherman \& Pavlou, 2003).

Perceived risks theory was previously examined when circumstances of the decision create (a) feelings of uncertainty (b) discomfort and/or anxiety (Dowling \& Staelin, 1994) (c) conflict aroused in the consumer (Bettman, 1973) (d) concern (e) psychological discomfort (Zaltman \& Wallendorf, 1983) (f) making the consumer feel uncertain (Engel, et. Al, 1986) (g) pain due to anxiety (Taylor, 1974) and (h) cognitive dissonance (Festinger, 1957). In this context, Featherman and Pavlou (2003) reviewed the facets of perceived risks to include risks associated with security, performance, financial, time, psychological and social aspects. Each of these perceived risks can be summarized into the following Figure 2.

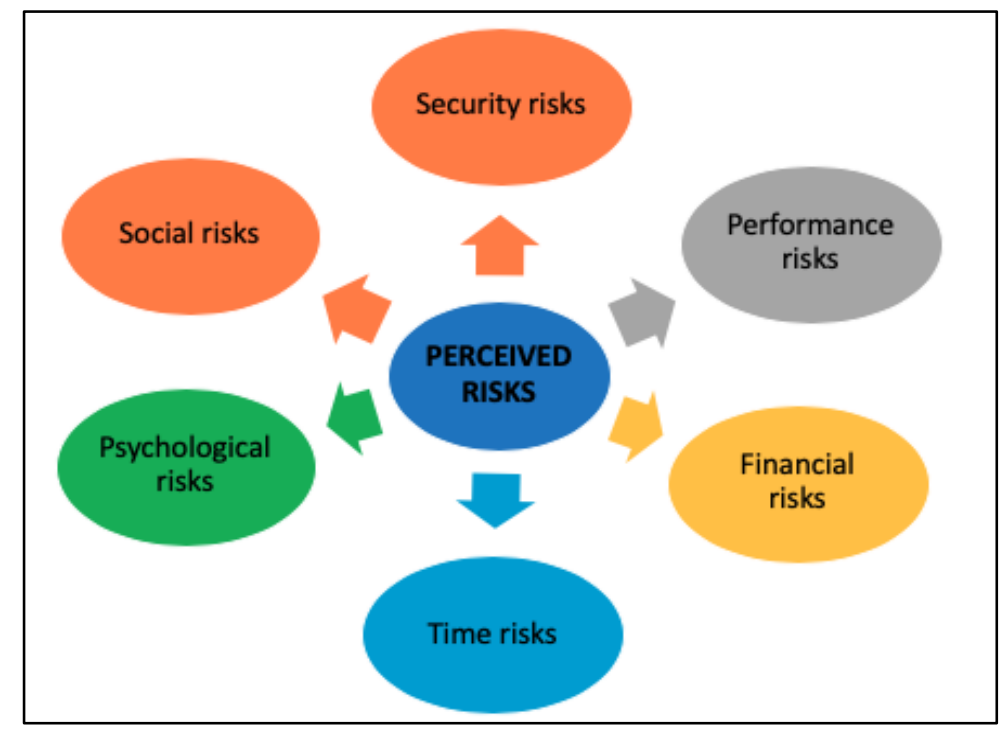

Figure 2. Facets of Perceived Risks

\section{Security Risk}

Traditionally, security risks involving the government would mean qualified guards watching over the government buildings, the protection of the security of the government officials, proper record keeping and management of the government documents. With the advent of the egovernment, the security infrastructure has become more complex. This risk in line with the theory of risk society, which is explained by Beck and Giddens. Beck (1992) who suggested that in the advanced modernity, the social production of wealth is systematically accompanied by the social production of risks. In other words, while the society is vigorously engaging in the information economy and knowledge economy, risks are inevitable to accompany the social production of wealth in the network society. Therefore, the consequences of scientific and industrial development are a set of risks and hazards, which are not limited by time and space (Beck, 1992). Following this view, Giddens (1994) asserts that manufactured risk is a new form of risk created by the evolution of human development and includes the growth of science and technology in the late modernity. 


\section{Performance Risk}

Performance risk means the possibility of the product becoming malfunctioned and not performing as it was designed and advertised and therefore failing to deliver the desired benefits. On this note, the question is whether technologies actually help or hurt the delivery of government services to the intended stakeholders.

\section{Financial risks}

Financial risks indicate the potential monetary outlay associated with the initial purchase price as well as the subsequent maintenance cost of the product. The current financial services research context expands this facet to include the recurring potential for financial loss due to fraud. The setting up full electronic government transactions would inevitably mean the involvement of additional costs, and it may prove to be a factor inhibiting their more widespread use of technological applications (Macdonald \& Wallace, 2004). Given the high costs involved, it is therefore imperative that budgeting and financial aspects in building up the whole egovernment system would need to be managed properly (Wong Peck, 2008).

\section{Time Risk}

Consumers may lose time when making a bad purchasing decision by wasting time researching and making the purchase, learning how to use a product or service only to have to replace it if it does not perform to expectations. Within the context of e-government, the learning curve of the new technologies installed at the government offices, the familiarization of using these technologies and trial and error process could possibly take some time, hence the users face time risks in dealing with all these technological applications in their work routines.

\section{Psychological Risks}

Psychological risks denote the risk that the selection or performance of the producer will have a negative effect on the consumer's peace of mind or self-perception. Essentially, a person faces the risk of potential loss of self-esteem (ego loss) from the frustration of not achieving an intended goal. Within the context of e-government, this risk applies in the sense that a user believes that he or she feels potential loss of self-esteem for his or her failure to complete a task intended by such technological applications, for instance electronic filing of government documents, online payments and record keeping.

\section{Social Risks}

Social risks mean potential loss of status in one's social group as a result of adopting a product or service, looking foolish or untrendy. The transformation from a conventional system of government into the adoption of modern technologies inevitably raised the issue of acquisition of skills and readiness of the government officials and industry practitioners. In this regard, it is contended that the successful implementation of the technologies requires the concerted effort of the parties involved in the particular industry, such as healthcare, education, enforcement units and the like. There is definitely the need for effective training for the government officers and the industry practitioners hence the need for a close liaison and good communication between the government and the stakeholders of the g-government services towards the implementation of e-government (Macdonald \& Wallace, 2004).

\section{Barriers to Implementation of E-Government}

Having described the various facets of risks perception theory in the previous section, this section outlines the numerous barriers to the implementation of e-government as reported in the literature. In this context, past literature had highlighted numerous barriers in implementing the 
e-government services. For example, a report by the e-government unit of the European Commission in 2007 identified seven main barriers to the e-government initiatives (Oxford Internet Institute, 2015), namely leadership failures, financial inhibitors, digital divides and choices, lack of coordination and harmonisation among the persons involved with the implementation of e-government, workplace and organisational inflexibility, lack of trust in the system itself, and poor technical design of the systems. Such barriers could be summarised into the following Figure 3.

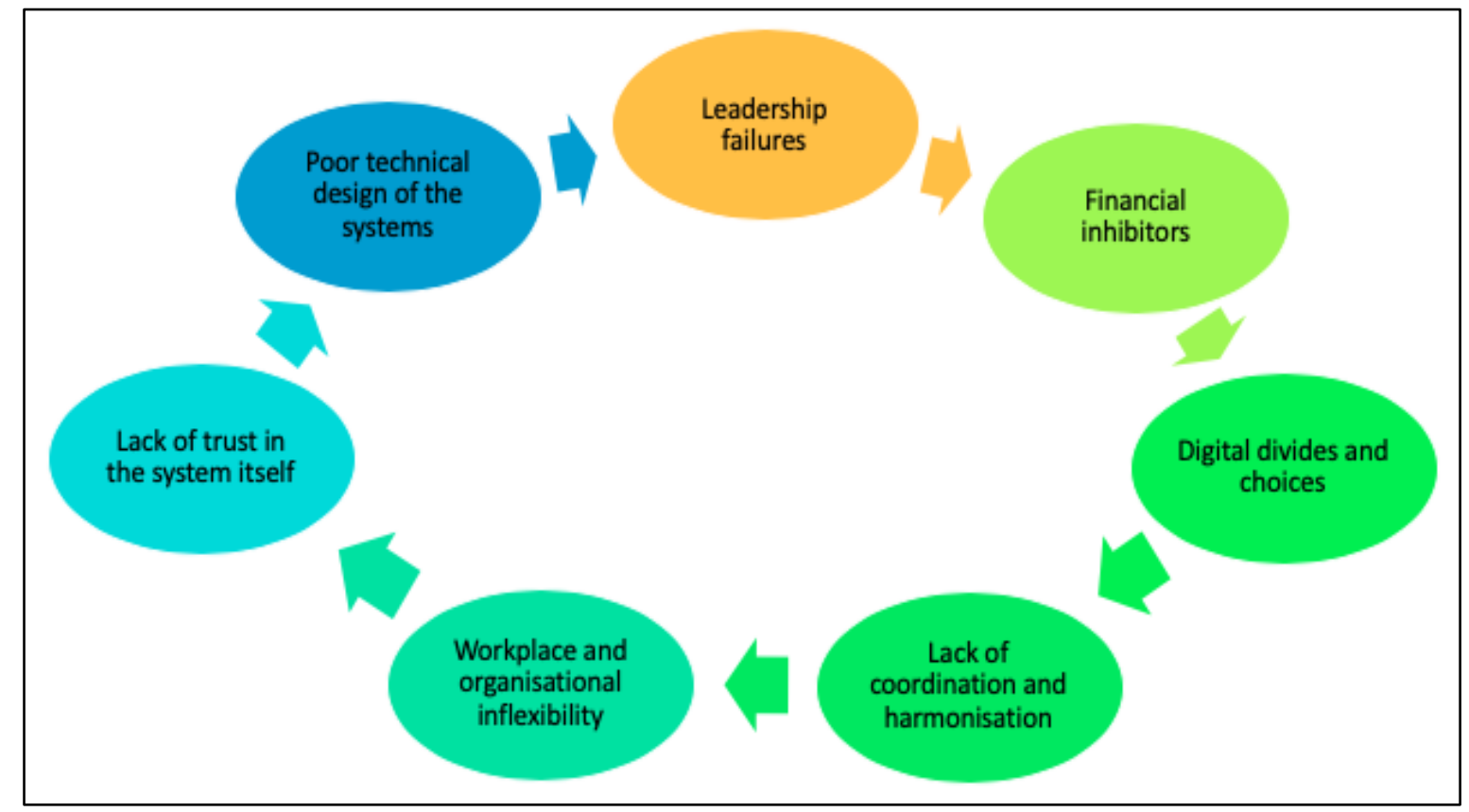

Figure 3. Barriers to E-Government

First, leadership failures hamper the implementation of e-government, in which slow and patchy progress to e-government can result from a lack of adequate leadership during any stage in the initiation, implementation, promotion and on-going support of developments. Accordingly, lack of support from politicians and high-level bureaucrats could add to this barrier (Moon \& Welch, 2005). Lukewarm support from high level decision-makers often leads to "stop and go" e-government progress and sustainability problems. The result is underdeveloped e-government platforms (Eyob, 2004).

The second barrier is financial inhibitors relating to concerns about the costs of implementing and developing e-government, together with inappropriate cost/benefit analysis approaches, can constrain or block the flow of investment at the levels necessary to support future e-government innovation (Oxford Internet Institute, 2015). In introducing e-government applications in the country, start-up costs could very well reach a huge amount, its maintenance also are to be regarded as recurrent (Ebrahim \& Irani, 2005). Not only that, human skills and trainings also need to be developed, which involves a considerable amount of time and costs. Admittedly, financial and human capital investments need to be made if e-government is to flourish (Eynon \& Dutton, 2007).

The third barrier to e-government is concerned with the digital divides and choices, which is caused by inequalities in skills and access can limit and fragment take-up of e-government. 
Failure to address clearly the needs of potential e-government users can also hamper take-up of e-government as even those citizens and businesses with appropriate levels of access may choose not to use available e-government services (Oxford Internet Institute, 2015). A clear example of this situation is the case of villagers living at places where broadband or internet services is not available due to distance or difficulty of installing the services. Understandably, what is more required by these people in such a situation is the search for livelihood and or access to basic necessities, as opposed to broadband services in order to access to e-government services (Helbig, Gil-García \& Ferro, 2009).

The fourth barrier is the poor coordination, involving lack of coordination and harmonisation, can put a halt on establishing appropriate e-government networks and services that cross governance, administrative and geographic boundaries (Oxford Internet Institute, 2015). Accordingly, more effort should be made by the government in order to determine clearly the proper coordination and harmonisation taking into account the different cultures (Carter \& Weerakkody, 2008; Margetts \& Dunleavy, 2002), societal factors and geographic boundaries available in the nation (Harfouche \& Robbin, 2015).

The fifth barrier relates to workplace and organisational inflexibility, within which the realisation of e-government benefits can be constrained or blocked by inflexibilities in responding to the need to make necessary changes in public administration practices, processes and organisational structures to allow them to be better able to make appropriate effective use of electronic networking capabilities (Oxford Internet Institute, 2015). On this note, a related barrier is the organisational or staff resistance, and the source of this resistance is the perception that technology replaces the need for people (Selwyn, 2002). In other words, if services can be provided via the Internet, the need for conventional office workers may decrease, thus resulting in fewer jobs. If individuals are fearful of being replaced by Internet applications, it is likely that these individuals will resist (Lam, 2005).

The sixth barrier is lack of trust, primarily caused by heightened fears about inadequate security and privacy safeguards in electronic networks and a general distrust of government can undermine confidence in e-government (Oxford Internet Institute, 2015). Government must ensure that personal information is kept confidential and secure. Not only the personal information of the employees of the government offices, but also the customer database of the products and services of the e-government are well exposed to privacy encroachment risks and therefore increases the public's lack of trust in e-government services (Guo \& Luo, 2015). In itself, the nature of e-government is the digitised information kept in the government offices' databases which makes it even easier to be transported or transferred from one database to another, hence proper and adequate measures would need to be in place to cater for these risks.

Another barrier to e-government is poor technical design, particularly relating to interoperability blockages caused by incompatibilities between ICT systems or difficult-to-use interfaces to e-government services exemplify the kinds of practical flaws that can become serious operational obstacles to take-up of what otherwise appear to be valuable e-government systems (Oxford Internet Institute, 2015). Interoperability is designed by the IT officers of the e-government system, and as such, they really would need to communicate with the real users in building their knowledge database for the actually needs and wants of the people, before they could introduce and incorporate the features and functions into the system (Pardo, Nam \& Burke, 2012). Failure to perform such proper investigation could pose as a barrier to the e- 
government, following the poor or difficult technical design of the e-government interfaces (Dos Santos \& Reinhard, 2011).

What could be learned from the numerous barriers to the implementation of e-government is that each of the barriers entail the understanding of the risk's perception theory, upon which such risks which could be perceived from the adoption of e-government services would in essence translated into the actual barriers itself. Henceforth, it is pertinent for the policy makers, the stakeholders and the citizens alike to understand the risks of the barriers to the e-government implementation, and strategically manage such risks to ensure its smooth running.

\section{Conclusion}

This paper had deliberated on the theorising of the risks perception theory in the understanding of the barriers to the implementation of e-government services. The appreciation of this theory is seen to be highly significant in explaining the various barriers to e-government, particularly, leadership failures, financial inhibitors, digital divides and choices, lack of coordination and harmonisation among the persons involved with the implementation of e-government, workplace and organisational inflexibility, lack of trust in the system itself, and poor technical design of the systems.

In essence, these barriers need to be appreciated along the lines of the risks perception theory in the consideration of e-government implementation for the benefit of the government itself, the stakeholders of the governmental business, and most importantly, the citizens. The direction for future research should henceforth empirically assess the abovementioned barriers so that real world data could facilitate the understanding of this subject matter in a better way.

\section{Acknowledgement}

This research is funded by University Grant (Geran Penjanaan) of Universiti Utara Malaysia.

S/O Code: 13940.

\section{References}

Barrett, M., Davidson, E., Prabhu, J., \& Vargo, S. L. (2015). Service Innovation in the Digital Age: Key Contributions and Future Directions. MIS Quarterly, 39(1), 135-154.

Bauer, R. (1967). Consumer behavior as risk taking. In D. Cox (Ed.), Risk Taking and Information Handling in Consumer Behavior. Cambridge, MA: Harvard University Press.

Beck, U. 1992. Risk Society: Towards a New Modernity. Sage Publications, London. P. 19.

Bettman, J. (1973). Perceived risk and its components: a model and empirical test. Journal of Marketing Research, 10(1), 184-190

Carter, L., \& Weerakkody, V. (2008). E-government adoption: A cultural comparison. Information Systems Frontiers, 10(4), 473-482.

Dahiya, D., \& Mathew, S. K. (2015). Impact of ICT Infrastructure Capability on E-Governance Performance: Proposing an Analytical Framework Emerging ICT for Bridging the Future-Proceedings of the 49th Annual Convention of the Computer Society of India (CSI) Volume 1 (pp. 603-610): Springer.

Dos Santos, E. M., \& Reinhard, N. (2011). Electronic government interoperability: Identifying the barriers for frameworks adoption.

Dowling, G., \& Staelin, R. A model of perceived risk and intended risk-handling activity. Journal of Consumer Research, 21(1), 119-134 
Ebrahim, Z., \& Irani, Z. (2005). E-government adoption: architecture and barriers. Business process management journal, 11(5), 589-611.

Engel, J., Blackwell, R., \& Miniard, P. (1986). Consumer Behavior. New York: CBS College Publishing.

Eynon, R., \& Dutton, W. H. (2007). Barriers to Networked Governments: Evidence from Europe 1. Prometheus, 25(3), 225-242.

Eyob, E. (2004). E-government: breaking the frontiers of inefficiencies in the public sector. Electronic Government, an International Journal, 1(1), 107-114.

Fang, Zhiyuan. "E-government in Digital Era: Concept, Development, and Practice." International Journal of the Computer 10.2 (2002): 1-22.

Featherman, M. S., \& Pavlou, P. A. (2003). Predicting e-Services Adoption: a Perceived Risk Facets Perspective. Int. J. Human-Computer Studies, 59(1), 451-474

Festinger, L. (1957). A Theory of Cognitive Dissonance. Stanford, CA.: Stanford University Press, Germunden, H. G. (1985). Perceived risk and information search: a systematic meta-analysis of empirical evidence. International Journal of Research in Marketing, 2(1), 79-100

Fugini, M. G., Maggiolini, P., \& Valles, R. S. (2015). e-Government and Employment Services: A Case Study in Effectiveness: Springer.

Giddens, A. 1994. Beyond Left and Right: The Future of Radical Politics. Polity Press, Cambridge. Pp. 4-7.

Guo, Y., \& Luo, Y. (2015). E-privacy Protection-Centering on Global Main Legal Instruments and Prospects Research on Selected China's Legal Issues of E-Business (pp. 91-106): Springer.

Harfouche, A., \& Robbin, A. (2015). E-Government Implementation in Developing Countries from Information to Smart Society (pp. 315-327): Springer.

Helbig, N., Gil-García, J. R., \& Ferro, E. (2009). Understanding the Complexity of Electronic Government: Implications from the Digital Divide Literature. Government Information Quarterly, 26(1).

Karim, M. A. (2003). Technology and Improved Service Delivery: Learning Points from the Malaysian Experience. International Review of Administrative Sciences, 69(2), 191204.

Lam, W. (2005). Barriers to e-government integration. Journal of Enterprise Information Management, 18(5), 511-530.

Macdonald, R., \& Wallace, A. (2004). Review of The Extent Of Courtroom Technology In Australia. Wm. \& Mary Bill of Rts. J., 12, 649, Weibel, M. M. (2002). Primer on Courtroom Technology. ABIJ, 21(6), 16

Margetts, H., \& Dunleavy, P. (2002). Cultural barriers to e-government. National Audit Office, $U K$.

Meijer, A. (2015). E-governance innovation: Barriers and strategies. Government Information Quarterly, 32(2), 198-206.

Mfoihaya, S. A., \& Yusof, M. M. (2015). E-Government project enquiry framework for a continuous improvement process, status in Malaysia and Comoros Information Science and Applications (pp. 125-133): Springer.

Moon, M. J., \& Welch, E. W. (2005). Same bed, different dreams? A comparative analysis of citizen and bureaucrat perspectives on e-government. Review of Public Personnel Administration, 25(3), 243-264.

Nasim, S. (2015). Interaction of Continuity and Change Forces and E-Government Performance Systemic Flexibility and Business Agility (pp. 63-81): Springer. 
Nograšek, J., Vintar, M., \& Irani, Z. (2015). Observing Organisational Transformation of the Public Sector in the E-Government Era. Transforming Government: People, Process and Policy, 9(1), 1.

Othman, R. (2005). The Analysis of Electronic Government Blueprint For Implementation Towards The Actual E-Government Implementation. (Msc. in IT), Unpublished Master's thesis. Universiti Utara Malaysia, Sintok Kedah.

Oxford Internet Institute, "Breaking Barriers to e-Government" online, available at http://www.oii.ox.ac.uk/research/projects/?id=14 accessed on 1 February 2015.

Pardo, T. A., Nam, T., \& Burke, G. B. (2012). E-government interoperability: Interaction of policy, management, and technology dimensions. Social Science Computer Review, 30(1), 7-23.

Peter, J., \& Ryan, M. (1976). An investigation of perceived risk at the brand level. Journal of Marketing Research, 13(1), 184-188

Rana, N. P., Dwivedi, Y. K., Williams, M. D., \& Weerakkody, V. (2015). Investigating success of an e-government initiative: Validation of an integrated IS success model. Information Systems Frontiers, 1-16.

Rita, P., \& Krapfel, R. (2015). Collaboration and Competition in Buyer-Supplier Relations: The Role of Information in Supply Chain and e-Procurement Impacted Relationships Assessing the Different Roles of Marketing Theory and Practice in the Jaws of Economic Uncertainty (pp. 98-105): Springer.

Schnoll, H. J. (2015). E-Government: Information, Technology, and Transformation: Information, Technology, and Transformation: Routledge.

Selwyn, N. (2002). 'E-stablishing'an inclusive society? Technology, social exclusion and UK government policy making. Journal of social Policy, 31(01), 1-20.

Siddiquee, N. A., \& Mohamed, M. Z. (2015). E-Government and Transformation of Service Delivery in Malaysia. International Journal of Public Administration in the Digital Age (IJPADA), 2(3), 45-60.

Tang, T., Hou, J., Fay, D. L., \& Annis, C. (2019). Revisit the drivers and barriers to egovernance in the mobile age: A case study on the adoption of city management mobile apps for smart urban governance. Journal of Urban Affairs, 1-23.

Taylor, J. (1974). The role of risk in consumer behavior. Journal of Marketing Research, 38(1), 54-60

United Nations Department of Economic and Social Affairs. Online, available at http://unpan3.un.org/egovkb/Portals/egovkb/Documents/un/2014-Survey/EGov_Complete_Survey-2014.pdf accessed on 1 March 2014.

Wescott, C. G. (2001). E-Government in the Asia-Pacific Region. Asian Journal of Political Science, 9(2), 1.

Wong Peck. (2008). E-Justice - Transforming the Justice System. Australian Institute of Judicial Administration Law \& Technology Conference, Sydney.

Yildiz, M. (2007). E-Government Research: Reviewing the Literature, Limitations, and Ways Forward. Government Information Quarterly, 24, 646-665.

Zaltman, G., \& Wallendorf, M. (1983). Consumer Behavior. New York: Wiley. 